\title{
Diffuse fibrosing alveolitis (diffuse interstitial fibrosis of the lungs): two cases with autoimmune features
}

\author{
I A N R. MACKAY AND BLAIR RITCHIE \\ From the Clinical Research Unit of the Walter and Eliza Hall Institute of Medical Research, \\ and the Pulmonary Laboratory of the University of Melbourne Department of Medicine, Royal \\ Melbourne Hospital, Victoria, Australia
}

This report describes two female patients with clinical, functional, and histological features suggestive of diffuse fibrosing alveolitis, and, in addition, serological findings indicative of an autoimmune reaction. The results of autoimmune serological tests in a further 15 patients are presented in tabular form. Read (1958b) presented detailed evidence supporting 'the concept that some cases of the Hamman-Rich syndrome are based on immune mechanisms'. Our findings suggest that diffuse fibrosing alveolitis could be caused by an autoimmune reaction, but our evidence is not conclusive. The term 'diffuse fibrosing alveolitis' has been used throughout this paper to include diffuse interstitial fibrosis and the Hamman-Rich syndrome according to the suggestions made by Scadding (1964) and Gough (1964).

\section{METHODS}

The methods used for pulmonary function studies were described by Ritchie (1964). Lung biopsies were obtained in both cases by Mr. L. Grigg by limited thoracotomy and surgical resection from the right middle lobe under general anaesthesia ; there were no complications. Cryostat sections of an unfixed portion of the lung biopsy from case 1 were treated with a fluoresceinconjugated goat anti-human $\gamma$-globulin serum and viewed under ultraviolet light to detect deposition of $\gamma$-globulin in the alveolar walls. Serological methods for anticytoplasmic antibodies (autoimmune complement fixation, AICF) and thyro-

I Working with the aid of a grant from the National Health and Medical Research Council of Australia

2 Present address: Clinical Pulmonary Physiology Research Unit, King's College Hospital Medical School. London S.E.5 globulin antibodies were those cited by Mackay and Wood (1962). Antinuclear factor was esti- $\mathscr{O}$ mated by immunofluorescence (Hasker, Mackay, and Miller, 1964) and rheumatoid factor by sensitized sheep cell agglutination (Alexander and de Forest, 1954).

\section{CASES STUDIED}

CASE 1 M.W., a woman aged 72 with diffuse fibrosing alveolitis and autoimmune haemolytic anaemia, presented in November 1961 with tiredness and pallor $=$ of three months' duration and progressive breathlessness on exertion of three weeks' duration: she was unable to walk further than 25 yards. Her past history included left-sided pleurisy 20 years previously and $x$ low back pain for 12 months. There had been no음 exposure to toxic inhalational irritants.

Examination revealed a thin, pale, slightly icteric $\delta$ woman with a respiratory rate of 26 per minute. 2 There were no abnormal cardiac or pulmonary find-을 ings and the fingers were not clubbed. The liver and spleen were palpable $2 \mathrm{~cm}$. below the costalo margin; the peripheral lymph nodes were not enlarged. There were no other significant physical on findings. Chest radiographs showed increased linear markings at both lung apices and osteoporosis with partial collapse of two thoracic and three lumbar $\tilde{\omega}$ vertebrae.

Laboratory investigations The haemoglobin level $\stackrel{\circ}{\frac{1}{(}}$ was $7.4 \mathrm{~g} . / 100 \mathrm{ml}$. and the reticulocyte proportion was $15 \%$. The serum bilirubin was $1.8 \mathrm{mg} . / 100 \mathrm{ml}$. The serum iron level was $102 \mathrm{mg} . / 100 \mathrm{ml}$. The serum haptoglobin level was $70 \mathrm{mg} . / 100 \mathrm{ml}$. The bone $\frac{\vec{D}}{\mathbb{D}}$ marrow showed active haemopoiesis, and $50 \%$ of the $\frac{\varrho}{1}$ cells were nucleated red cells. The direct Coombs' test was positive. Red cell fragility tests gave normalo results. The L.E. cell test was negative on five occa-sions. The Wassermann reaction was negative. The 
total serum protein level was $6.5 \mathrm{~g} . / 100 \mathrm{ml}$., the albumin level being $3.4 \mathrm{~g}$. and the $\gamma$-globulin $1.2 \mathrm{~g} . /$ $100 \mathrm{ml}$

Course of illness Treatment with prednisolone, initially $60 \mathrm{mg}$. daily followed by a maintenance dose of $30 \mathrm{mg}$. daily, produced a rise in the haemoglobin level to $13.9 \mathrm{~g} . / 100 \mathrm{ml}$. and a fall in the reticulocyte level to $2 \%$. The direct Coombs' test became negative. Treatment with prednisolone was stopped after six weeks. Two months later the patient complained of severe breathlessness on exertion, of three weeks' duration, and she appeared pale and dyspnoeic at rest: the respiratory rate was 24 per minute. Crepitations were then audible at both lung bases. The haemoglobin level had fallen to $9 \cdot 1 \mathrm{~g} . / 100 \mathrm{ml}$. and the reticulocytes were $12 \%$. The direct Coombs' test was again positive. The $50 \%$ survival time of red cells labelled with radioactive chromium $\left({ }^{51} \mathrm{Cr}\right)$ was eight days, the normal being 25 to 36 days, and surface counting demonstrated increased destruction of red cells in both the spleen and liver. Treatment with prednisolone, $60 \mathrm{mg}$. daily, was recommenced. Over five weeks the haemoglobin level rose to $12.8 \mathrm{~g}$./ $100 \mathrm{ml}$., the prednisolone dosage being reduced to $10 \mathrm{mg}$. daily. On this dosage the reticulocyte level ranged from $4 \%$ to $15 \%$ and the direct Coombs' test remained positive.

One month later, in May 1962, she complained of progressively increasing breathlessness on exertion and left pleuritic chest pain. Examination showed orthopnoea, no cyanosis, a respiratory rate of 28 per minute, and crepitations at both lung bases. The chest radiograph was unchanged. The haemoglobin level was 12.4 g. $/ 100 \mathrm{ml}$., and the direct Coombs' test was positive. The Mantoux reaction was negative to $1 / 100$ of old tuberculin. Sputum cultures for $\mathrm{Myco}$ bacterium tuberculosis and other pathogens were negative. A liver biopsy showed normal liver tissue.

During the succeeding two years she sustained a subcapital fracture of both femora but otherwise maintained fair health, the haemolysis being controlled by $10 \mathrm{mg}$. of prednisolone daily. However, cessation of prednisolone treatment was followed by an exacerbation of haemolysis and terminal bronchopneumonia.
Pulmonary function studies (Table I) In May 1963 these showed a restrictive ventilatory defect, a reduction in lung volumes, arterial oxygen desaturation at rest, and a low arterial carbon dioxide tension; oxygen desaturation increased with exercise; the diffusing capacity for carbon monoxide and lung compliance was reduced.

Lung biopsy (Fig. 1) A biopsy from the right middle lobe showed distended alveoli containing desquamated cuboidal alveolar cells and thickening of the alveolar walls by eosinophilic material, fibrous tissue, and

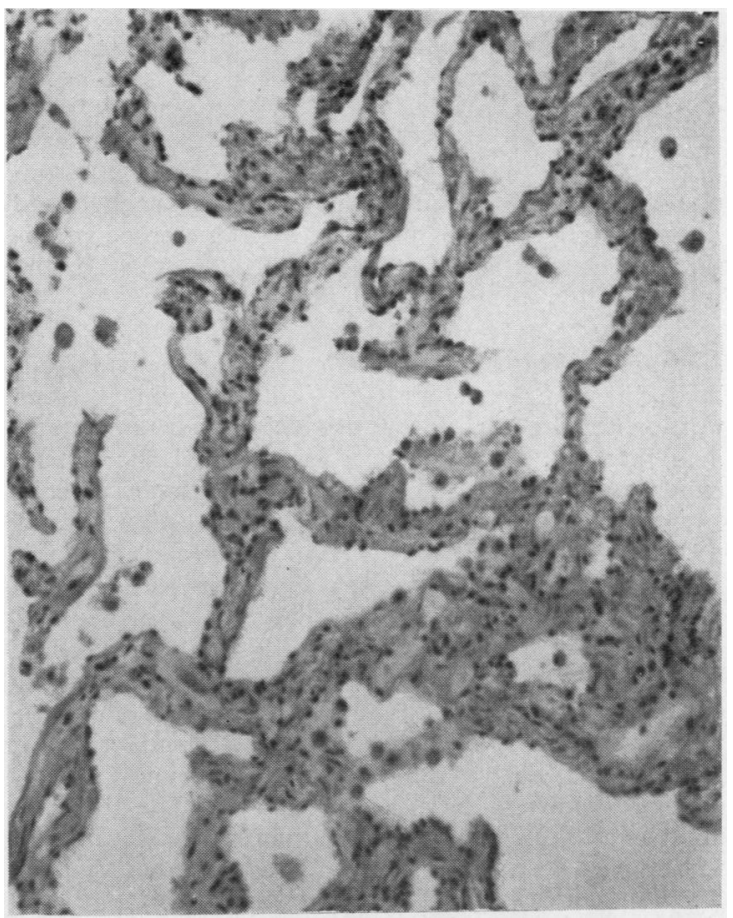

FIG. 1. Case 1. Lung biopsy showing desquamation of alveolar cells and thickening of alveolar walls with eosinophilic material. $H$. and $E$., $\times 130$.

TABLE I

PULMONARY FUNCTION TESTS IN CASES 1 AND 2

\begin{tabular}{|c|c|c|c|c|c|c|c|c|c|c|}
\hline & \multirow{2}{*}{$\begin{array}{l}\text { Vital Capacity } \\
\text { (V.C.) }\end{array}$} & \multirow{2}{*}{ F.E.V.V.1・0 } & \multirow{2}{*}{$\begin{array}{c}\text { F.E.V.1.0 } \\
\text { as } \\
\% \text { of } \\
\text { V.C. }\end{array}$} & \multirow{2}{*}{$\begin{array}{c}\text { Total } \\
\text { Lung } \\
\text { Capacity }\end{array}$} & \multirow{2}{*}{$\begin{array}{l}\text { Residual } \\
\text { Volume } \\
\% \text { of } \\
\text { T.L.C. }\end{array}$} & \multirow{2}{*}{$\begin{array}{c}\text { Single- } \\
\text { breath Co } \\
\text { Diffusing } \\
\text { Capacity } \\
\text { (ml. min./ } \\
\text { mm. Hg) }\end{array}$} & \multirow{2}{*}{$\begin{array}{c}\text { Com- } \\
\text { pliance } \\
(1 . / \mathrm{cm} . \\
\left.\mathbf{H}_{2} \mathrm{O}\right)\end{array}$} & \multicolumn{2}{|c|}{$\underset{\text { Saturation }}{\mathrm{O}_{2}}$} & \multirow{2}{*}{$\begin{array}{c}\mathrm{PCO}_{2} \\
\text { (Rest) } \\
\text { (mm. } \\
\mathbf{H g} \text { ) }\end{array}$} \\
\hline & & & & & & & & Rest & Exercise & \\
\hline Case 1 & $2 \cdot 35(3 \cdot 25)$ & 1.61 & $68 \cdot 5(>70)$ & $3.66(4 \cdot 72)$ & $36(47)$ & $9.6(18.5)$ & $0.08(0 \cdot 10)$ & 90 & 82 & 32 \\
\hline Case 2 & $\begin{array}{ll}\text { October } 1962 & 1 \cdot 40(2 \cdot 50) \\
\text { July } 1964 & 1.89\end{array}$ & $\begin{array}{l}1 \cdot 27 \\
1 \cdot 78\end{array}$ & $\begin{array}{l}90 \cdot 7(>70) \\
94 \cdot 2\end{array}$ & $\begin{array}{l}2 \cdot 75(5 \cdot 00) \\
3 \cdot 13\end{array}$ & $\begin{array}{l}49(39) \\
40\end{array}$ & $\begin{array}{c}9 \cdot 3(19 \cdot 8) \\
18 \cdot 3\end{array}$ & $\begin{array}{l}0.02(0.06) \\
0.016\end{array}$ & 94 & 68 & 30 \\
\hline
\end{tabular}

Gas volumes expressed in litres, B.T.P.S. Predicted values appear in brackets. Neither patient showed a significant change in V.C. or F.E.V. after a bronchodilator aerosol. 
moderate numbers of lymphocytes: there were considerably increased amounts of elastic tissue and reticulin. The smaller pulmonary vessels showed pronounced muscular hypertrophy. Cultures made from portions of the lung biopsy for bacteria, viruses, and mycoplasma all yielded no growth.

Immunological studies The serum $\gamma$-globulin level. which ranged from 1.2 to $1.5 \mathrm{~g} . / 100 \mathrm{ml}$., was not raised. The Coombs' reaction was positive throughout most of the illness. The titre of antithyroglobulin ranged from $1 / 7,000$ to $1 / 15,000$, although there was no clinical evidence of thyroid dysfunction. Tests for antinuclear antibody (L.E. cell reaction), anticytoplasmic antibody, and rheumatoid factor were negative. Treatment of frozen sections of the lung biopsy with fluorescein-labelled antiglobulin serum showed considerably increased amounts of fluorescent material in the alveolar walls as compared with sections from control subjects; however, a high background fluorescence in this lung, due to increased autofluorescent elastic tissue, led to difficulties in the interpretation of the above findings.

Necropsy This showed death to have resulted from bilateral bronchopneumonia. Sections from various portions of the lungs showed widely differing changes, including an abscess walled by fibroblastic tissue, exudation of fibrin and macrophages into the alveoli. extensive bronchopneumonia, congestion, and oedema. Many small vessels contained recent thrombi. and many of the larger vessels showed recent thrombi on top of old organized thrombus. In less involved areas of lung there were many thick-walled vessels. some with hyaline changes, others with organized and recanaiized areas. Practically throughout the lung there were narrow thick-walled vessels, and in many places there was some increase of surrounding connective tissue with scattered leucocytes. The thickening spread into the walls of many alveoli, and in some areas there appeared to be a proliferation also of smooth muscle. Features of diffuse fibrosing alveolitis in the less involved areas consisted of thickening of the walls of alveoli. proliferation of smooth muscle, and general infiltration with both polymorphonuclear leucocytes and 'round cells' of slight to moderate degree; there had been no significant progression of the lesion as compared with the previous biopsy.

Additional findings included erythroid hyperplasia, adrenal atrophy. and a colloid goitre, but there was no significant lymphoid infiltration in the thyroid gland despite the raised antithyroglobulin titre. There were no other significant findings.

CASE 2 F. A., a woman aged 49 with diffuse fibrosing alveolitis, hyper- $\gamma$-globulinaemia, and a high-titre autoimmune complement fixation reaction, complained of progressive shortness of breath and a weight loss of $20 \mathrm{~kg}$. of 18 months' duration. She had had a non-productive cough for three months, and then developed a severe pain in the left chest and $\stackrel{\overrightarrow{\vec{S}}}{\vec{P}}$ increasing dyspnoea. There was no relevant past his- 0 tory and no exposure to toxic inhalants.

Examination showed dyspnoea at rest, a respira-

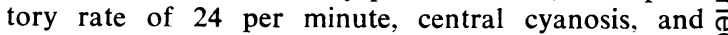
clubbing of the fingers. On auscultation generalized crepitation and high-pitched wheezes were audible 8 over most of the chest. There were no other signi- $\vec{\circ}$ ficant physical findings. The chest radiograph revealed a diffuse reticular and nodular pattern over the lower two-thirds of both lung fields.

Laboratory investigations The haemoglobin level was $11 \cdot 3 \mathrm{~g} . / 100 \mathrm{ml}$.; the white cell count was 11,000 per c.mm. The erythrocyte sedimentation rate was i $20 \mathrm{~mm}$. in one hour (Westergren). The total serum 8 protein level was $8.6 \mathrm{~g} . / 100 \mathrm{ml}$., the albumin level being $3.1 \mathrm{~g} . / 100 \mathrm{ml}$. and the $\gamma$-globulin level $2.9 \mathrm{~g}$./ $100 \mathrm{ml}$. The Mantoux reaction was negative to $1 / 100$ of old tuberculin. Sputum cultures for acid-fast bacilli were negative.

Pulmonary function studies (Table I) These indi- o cated a restrictive ventilatory defect, there being arterial oxygen desaturation at rest, becoming pronounced with mild exercise. The diffusing capacity for carbon monoxide and lung compliance was reduced.

Lung biopsy The alveolar walls were thickened by loose fibrous tissue and were densely infiltrated with cells of varying types, including eosinophils, lymphocytes, and plasma cells (Fig. 2).

Immunological studies The $\gamma$-globulin level was raised to $2.9 \mathrm{~g}$. $/ 100 \mathrm{ml}$. The Coombs' reaction was negative. Tests for rheumatoid factor and aritithyroglobulin antibrdy were negative. The L.E. cell preparation showed tart cells but no L.E. cells. The immunofluorescence test for antinuclear factor was 3 weakly positive. The complement fixation test for anticytoplasmic antibody was strongly positive, the serum titre with liver antigen being $1 / 32$ and with kidney antigen $1 / 512$. Immunofluorescence studies were not performed on the tissue obtained at lung biopsy.

Course of illness She was treated with prednisolone, $45 \mathrm{mg}$. daily initially, and $10 \mathrm{mg}$. as a maintenance dosage. This led to subjective improvement and disappearance of the adventitious sounds in the chest, but there was no change in the chest radiographic appearances. After 21 months she still suffered from dyspnoea on mild exertion and required $10 \mathrm{mg}$. of prednisolone daily: there was some slight improvement in the indices of pulmonary function (Table I).

CASES 3 To 17 A full series of tests for autoantibodies was performed on sera from a further 15 patients with diffuse interstitial lung disease. These were members of a group being studied by Gandevia and Ritchie (1965): patients with the clinical features of 


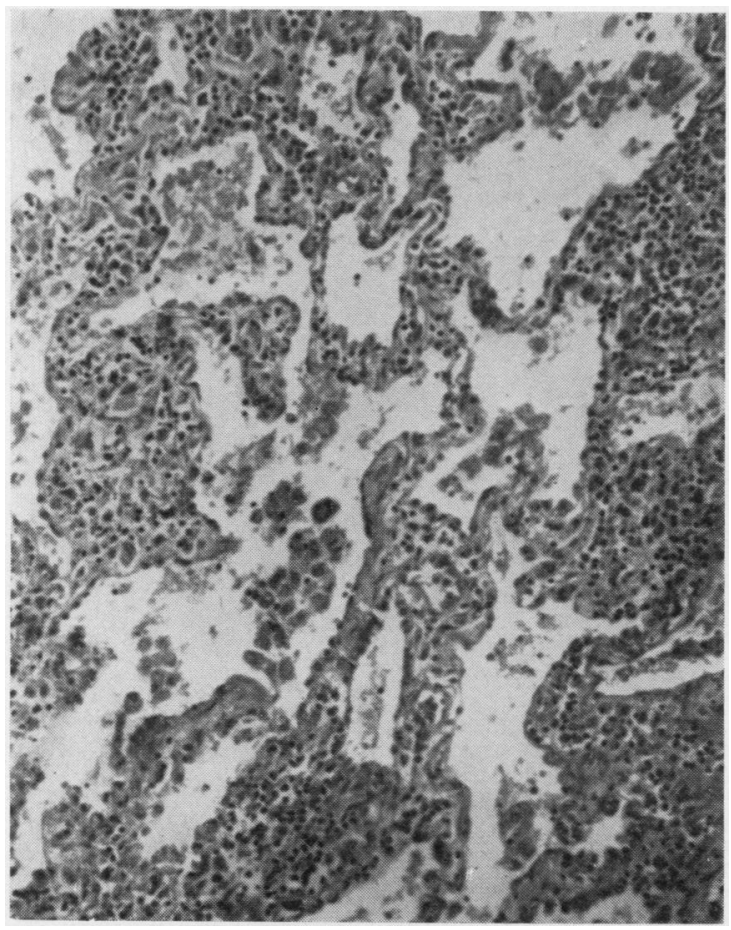

FIG. 2. Case 2. Lung biopsy showing gross thickening of the alveolar walls by loose fibrous tissue and accumulations of lymphoid cells. $H$. and $E$., $\times 160$.

rheumatoid arthritis, scleroderma or systemic lupus erythematosus were specifically excluded from this particular group. Of the 17 patients studied (Table II), three had hyper- $\gamma$-globulinaemia (level $>1.5 \mathrm{~g} . /$ $100 \mathrm{ml}$.), seven (41\%) gave a weakly positive test for antinuclear factor, three (18\%) had a positive A.I.C.F. reaction for anticytoplasmic antibody, four (24\%) gave a positive reaction for rheumatoid factor, and two had highly elevated titres of antithyroglobulin.

TABLE II

INCIDENCE OF POSITIVE AUTOIMMUNE SEROLOGICAL TESTS IN 17 CASES OF DIFFUSE FIBROSING ALVEOLITIS

\begin{tabular}{|c|c|c|c|c|}
\hline \multirow[b]{2}{*}{ Test } & & \multirow{2}{*}{$\underset{\substack{\text { Critical } \\
\text { Serum } \\
\text { Dilution' }}}{ }$} & \multicolumn{2}{|c|}{ Incidence of Positive Results } \\
\hline & & & $\begin{array}{c}\text { Controls } \\
(\%)\end{array}$ & $\begin{array}{c}\text { Cases } \\
\text { Studied (\%) }\end{array}$ \\
\hline Antinuclear factor & . & & 8 & 41 \\
\hline A.I.C.F. ${ }^{2}$ & . & 18 & 3 & 18 \\
\hline Rheumatoid factor & .. & 164 & 2 & 24 \\
\hline Antithyroglobulin & 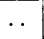 & $1 / 100$ & 4 & 18 \\
\hline
\end{tabular}

Minimum serum dilution for positive result

2 Antigens used included human liver, kidney, and lung; with positive sera, titres to lung antigen were not greater than titres to liver and kidney antigen

\section{DISCUSSION}

There is considerable interest at present in the immunological aspects of several seemingly unrelated chronic pulmonary diseases, including idiopathic pulmonary haemosiderosis, nephritis with pulmonary haemorrhage, pulmonary granulomatosis, pulmonary eosinophilia, and diffuse fibrosing alveolitis (diffuse interstitial fibrosis of the lung). The latter, exemplified by the present cases, may be relatively acute (Hamman and Rich, 1944), but is more frequently chronic (Scadding, 1960): an apparently similar process in the lungs may occur in certain chronic systemic diseases, notably rheumatoid arthritis. We are in harmony with Spencer (1962), who stated that it was "singularly unfortunate that the term "collagen disease" had come to be applied to this group of disorders ${ }^{1}$ as it is both misleading and fails to indicate the probable underlying abnormality, which is likely to be a disordered immunity reaction'. On the other hand, there is the recent statement (Lancet, 1964) that the cause of diffuse fibrosing alveolitis is still considered to be unknown.

The evidence for an autoimmune process being a cause of diffuse fibrosing alveolitis can be reviewed under the headings of hyperglobulinaemia, autoantibodies, cellular infiltration, corticosteroid response, multisystem involvement, and experimental analogues, as follows.

HYPERGLOBULINAEMIA This was exemplified by only three of our 17 patients, and, although reported by several authors, was regarded as a 'rare association' by Livingstone, Lewis, Reid, and Jefferson (1964).

AUTOANTIBODIES Autoantibodies of various types are demonstrable in a proportion of patients with diffuse fibrosing alveolitis. Antinuclear antibodies may be present as shown by a positive test for L.E. cells (Braunsteiner, Egghart, and Potuzhek, $1960)$ or antinuclear factor. The rheumatoid factor, which is an auto-antibody to $\gamma$-globulin, is often present with or without clinical evidence of rheumatoid arthritis, and rheumatoid arthritis may supervene after the onset of diffuse fibrosing alveolitis (Lee and Brain, 1962) ; contrary to Scadding's approach (1960), we would not necessarily exclude cases from the group on the basis of their having rheumatoid arthritis or a positive serological test for rheumatoid factor. Erythrocyte autoantibodies, antithyro-

1 Progressive systemic sclerosis, Hamman-Rich lung, and rheumatoid disease 
globulin, and anticytoplasmic antibodies were demonstrable in our two index cases. However, although the incidence of positive autoimmune serological tests in our full series of cases was greater than that in control subjects, it fell short of the incidence of positive tests in more florid immunopathies such as systemic lupus erythematosus, lupoid hepatitis, and Hashimoto's thyroiditis: thus no firm conclusions can be drawn from our present findings. It should be noted that the titres of complement-fixing autoantibodies to lung did not exceed the titres to liver and kidney, suggesting that circulating lung-specific autoantibodies are not concerned in the pathogenesis of diffuse fibrosing alveolitis.

CELlULAR INFILTRATION Autoimmune lesions are characterized histologically by infiltration with lymphocytes, plasma cells, and occasionally eosinophils, these being the cell types characteristically associated with immune responses: such infiltration is seen frequently in diffuse fibrosing alveolitis (Gandevia and Ritchie, 1965). The characteristic terminal fibrosis could well be a relatively late development, since the lung in early phases of the disease is seldom available for microscopic examination.

The lung biopsies of cases 1 and 2 presented rather different lesions. The changes in case 1 of eosinophilic interalveolar thickening with minimal cellular infiltration could be interpreted as possibly resulting from deposition of antigenantibody complex, analogous perhaps to the lesion of membranous glomerulonephritis. In case 2 , on the other hand, there was a heavy interalveolar infiltration with cells-lymphocytes and plasma cells, occasionally present as focal aggregates, and plentiful eosinophils.

CORTICOSTEROID RESPONSE A response to corticosteroid drugs characterizes most autoimmune conditions. Corticosteroids are said to produce improvement in at least some patients with diffuse fibrosing alveolitis (see Bates, 1962) and this was also the experience of Livingstone et al. (1964) and of Gandevia and Ritchie (1965) in their study of the present cases. Our cases 1 and 2 both reached the state of corticosteroid dependence with apparent arrest of the disease, and some improvement in pulmonary function tests occurred in case 2.

MULTISYSTEM INVOLVEMENT It is significant that fibrosing alveolitis can occur as part of a widespread disease process: it may be associated with Coombs' positive haemolytic anaemia as in our first case, rheumatoid arthritis, progressive systemic sclerosis, and, rarely, with dermatomyositis (Hyun, Diggs, and Toone, 1962), Sjögren's disease (Tomasi, Fudenberg, and Finby, 1960), and chronic hepatitis (Heppleston, 1956; Scadding, 1960). Moreover, features suggestive of a 'multisystem disorder', including tachycardia, arthralgia, and fever, may be encountered in the absence of evidence of the specific diseases referred to above (Gandevia and Ritchie, 1965).

EXPERIMENTAL DISEASE The most relevant experimental evidence is that of Read (1958a) who, working with rats, produced changes in the lungs resembling human diffuse fibrosing alveolitis by intra-tracheal instillation of a 'pneumonotoxic' rabbit anti-rat lung serum.

Were an autoimmune process to be implicated in diffuse fibrosing alveolitis, on the basis of positive serological reactions in some patients, the actual pathogenesis of the alveolar lesions is uncertain. We would not implicate lung-specific autoantibodies in our patients. Tomasi et al. (1960) favoured deposition of antigen-antibody complexes in the pulmonary capillaries, at least in the type of disease associated with rheumatoid arthritis, and suggested the application of fluorescent antibody techniques to detect deposited $\gamma$ globulin in the lungs; our immunofluorescence results in case 1 were inconclusive, and even positive findings would need to be interpreted with caution in view of the possibility of the nonimmune deposition of serum globulins in diseased lung tissue.

Our present limited data, together with the findings of others, call for further investigation into the rôle of immunological factors in diffuse interstitial pulmonary fibrosis. This might include a clearer definition of the frequency with which diffuse fibrosing alveolitis is associated with the diseases classifiable as 'immunopathies', a more detailed assessment of the therapeutic value of corticosteroids and possibly of lymphocytotoxic N agents, a full study of lung tissue obtained by $N$ operative biopsy, including culture for bacteria, N mycoplasma, and viruses, and immunofluor- $\omega$ escence reactions, and finally further observations on animals with lung disease produced experimentally by means of anti-lung serum.

\section{SUMMARY}

Two patients with clinical, functional, and histological features of diffuse fibrosing alveolitis had serological evidence of autoimmune reactions. Serological tests for autoantibodies in a further 8 
15 patients with diffuse fibrosing alveolitis showed a moderate incidence of positive reactions. The evidence for autoimmunization as a cause of this lung disease, although not decisive, does call for further studies on the rôle of immune mechanisms.

We are indebted to Professor R. R. H. Lovell, Dr. A. E. Doyle, Dr. Margaret Henderson, and Dr. B. L. Marks for generously permitting us to study patients under their care. Professor B. Gandevia kindly sent us sera from patients with diffuse fibrosing alveolitis, and assisted in the preparation of the manuscript. We are greatly indebted to Dr. J. D. Hicks for pathological interpretations and to Miss Nancy Rogers for assisting with measurements of pulmonary function.

\section{REFERENCES}

Aexander, R., and de Forest, G. K. (1954). The sensitized sheep cell agglutination reaction in rheumatoid arthritis. Amer. J. Med., 16, 191.

Bates, D. V. (1962). Respiratory disorders associated with impairment of gas diffusion (alveolo-capillary block syndrome). Ann. Rev. Med., 13, 301.
Braunsteiner, H., Egghart, F., and Potuzhek, O. (1960). Primär chronische Polyarthritis mit chionischen pulmonalen Veränderungen. Dtsch. med. Wschr., 85, 115.

Gandevia, B., and Ritchie, B. (1965). In preparation.

Gough, J. (1964). Correspondence. Brit. med. J., 2, 818.

Hamman, L., and Rich, A. R. (1944). Acute diffuse interstitial fibrosis of the lungs. Bull. Johns Hopk. Hosp. 74, 177.

Hasker, J., Mackay, I. R., and Miller, J. J. (1964). The incidence of antinuclear factor in human disease. Submitted for publication

Heppleston, A. G. (1956). The pathology of honeycomb lung. Thorax, $11,77$.

Hyun, B. H., Diggs, C. L., and Toone, E. C. Jr. (1962). Dermatomyositis with cystic fibrosis (honeycombing) of the lung. Case report. Dis. Chest 42, 449.

Lancet (1964). Diffuse interstitial pulmonary fibrosis. Lancet, 1, 1202.

Lee, F. I., and Brain, A. T. (1962). Chronic diffuse interstitial fibrosis and rheumatoid arthritis. Ibid., 2, 693.

Livingstone, J. L., Lewis, J. G., Reid, L., and Jefferson, K. E. (1964). Diffuse interstitial pulmonary fibrosis. A clinical, radiological, and pathological study based on 45 patients. Quart. J. Med., N.S., 33, 71.

Mackay, I. R., and Wood, I. J. (1962). Lupoid hepatitis : A comparison of 22 cases with other types of chronic liver disease. Ibid., 31, 485 .

Read, J.'(1958a). The pathological changes produced by anti-lung serum. J. Path. Bact., 76, 403.

- (1958b). The pathogenesis of the Hamman-Rich syndrome. Amer. Rev. Tuberc., 78, 353.

Ritchie, B. (1964). Pulmonary function in scleroderma. Thorax, 19, 28.

Scadding, J. G. (1960). Chronic diffuse interstitial fibrosis of the lungs. Brit. med. J., 1, 443.

(1964). Correspondence. Ibid., 2, 686.

Spencer, H. (1962). Pathology of the Lung, p. 604. Pergamon Press, Oxford.

Tomasi, T. B., Jr., Fudenberg, H. H., and Finby, N. (1960). Possible relationship of rheumatoid factors and pulmonary disease.
Amer. J. Med., 33, 243 . 